\title{
Lessons from family firms: the use of flexible work arrangements and its consequences
}

\author{
Isabell K. Stamm ${ }^{1} \cdot$ Fabian Bernhard ${ }^{2}$ (D) $\cdot$ Nicole Hameister $^{3} \cdot$ Kristel Miller $^{4}$
}

Received: 2 May 2021 / Accepted: 1 December 2021 / Published online: 5 January 2022

(c) The Author(s), under exclusive licence to Springer-Verlag GmbH Germany, part of Springer Nature 2021

\begin{abstract}
Ongoing trends towards more flexible work arrangements (FWA) have been accelerated by the Covid-19 crisis. Whilst research has shown the overall benefits FWA can have, limited research has explored whether use and benefits of FWA are equal across differentiated organisational contexts and genders. We suggest that individuals working in their family's business face less organizational constraints that typically hinder employees from taking advantage of FWA. It could be suggested that these workers may make higher use of FWA than individuals in regular employment because of their entrepreneurial status and nepotistic privileges. Consequently, the aim of this paper is to explore if family members working in their family's business, work under favourable boundary conditions which enable them to more freely make use of and benefit from FWAs. Utilising representative data from the German Family Panel (pairfam), our comparative analysis based on propensity score matching, suggests that family members working in their family's business $(\mathrm{N}=337)$ do make greater use of FWA than those in regular employment. Counter to common assumptions, the findings reveal that FWA leads to higher workloads for owner-managers but not for family employees. Furthermore, families working in their business show no differences in how they divide household tasks compared to regular employed families-yet they perceive that division to be fairer. This study extends knowledge by introducing family ownership and kinship ties as important boundary conditions to existing theories on FWA, such as life-course theory. It also provides new insights into the commonly assumed consequences of FWA use.
\end{abstract}

Keywords Flexible work arrangements · Family business · Gender equality · Workload · Flexibility

Fabian Bernhard

fabian.bernhard@edhec.edu

Extended author information available on the last page of the article 


\section{The use of flexible work arrangements and its consequences: lessons from families in business}

\subsection{Introduction}

The past years have seen a significant increase in organisations offering flexible work arrangements (FWA) to employees. FWA covers a range of options but most frequently refer to flexitime (i.e., compressed working weeks or variations in start and finish time each day) and home office/teleworking, where employees work from home for part or all of the working week, making use of technology to stay connected to the workplace (Peretz et al. 2018). The Covid-19 crisis, which enforced working from home for many sectors, has accelerated remote working trends. A recent study by McKinsey (2020) identifies that many employers are planning to reduce office space up to $30 \%$ in anticipation of moving to more FWA. Prior research attributes numerous benefits for both employees and employers utilising FWA. In particular, it has been suggested to help alleviate gender inequalities which women often face in the workplace (Kelly and Moen 2020; Kelly et al. 2019; Chung and van der Lippe 2020; Thébaud and Halcomb 2019). For example, in Germany, flexible working has been promoted by policy-makers as an effective mechanism to facilitate the integration of women back into the workforce after childbirth (Grunow et al. 2006; Allmendinger and Ebner 2006). Flexible working has been suggested to help shift gender norms, through decreasing work- life conflict (Kelly and Moen 2007a, b; Kim and Gong 2016; Munsch 2016) and can help alleviate the gender pay gap. FWA has also been found to increase employee commitment to an organisation (De Menezes and Kelliher 2017,2011).

However, Chung and van der Lippe (2020) caution that the actual consequences of FWA are varied. For example, it has been suggested that FWA can actually reinforce gender stereotypes, where the ability to extend the working day is not equal between genders. Therefore, FWA can in fact lead to an increased workload for women (Kelly and Moen 2020; Correll et al. 2014; Lott and Chung 2016). It is suggested that FWA will not automatically lead to specific outcomes, but it is dependent upon the actual use of FWA by organizational members (Allen et al. 2013). Effective FWA requires integration into organizational cultures, structure and norms, otherwise, it can result in additional workloads on top of regular roles, resulting in role overload (Kelly and Moen 2020; Kelly et al. 2011). Moen (2015) suggests that FWAs require an "organizational turn" in order to avail of the positive effects of flexible working.

With the increased prevalence of organisations moving to FWA, we argue that there is a need to identify and explore the boundary conditions of FWA, where we suggest that differentiated contexts will impact both the ability to engage in FWA and its outcomes. Alongside gender, it could be suggested that different organisational forms, such as family businesses may increase the accessibility of FWA for particular employees, such as family member employees working within their family businesses. Consequently, the aim of this research is to explore if family member employees working in their family's business, work under 
favourable boundary conditions which enable them to more freely make use of and benefit from FWAs. To achieve this, we employ the strategy of "theory borrowing' (Markoczy and Deeds 2009) from sociology, to combine concepts from life course theory, which reflects upon the intertwinement of different life sphere across life (Moen and Orrange 2002; Moen and Roehling 2005; Kohli 2007; Elder et al. 2003) with current literature on FWA and family businesses. This allows for the deductive testing of "a variety of assumptions about the inherent tensions between family and work organization" (Kanter 1977, 55). In particular, we analyse whether FWA increases an individual's workload and whether it can lead to more gender equality, specially relating to the equal division of work at home.

Our study contributes to novel insights into the consequences of FWA use, through learning from a specific context where individuals are more likely to make use of FWA, namely individual family members working in their family's business. Specifically, we test the extent to which close tie relationships to others within the organisational network (such as family ties) constitute an important, yet previously overlooked factor relating to the use of FWAs. We argue that family ownership, kinship ties and relationships may represent important boundary conditions to existing theories on FWA. Furthermore, we suggest that previous studies may have overstated the positive consequences of FWA as a vehicle to achieve work intensification and greater gender equality.

\section{Key literature concepts and hypotheses}

\subsection{Structural lag leading to constraints on work flexibility}

A sociological theory of the life course suggests that a historical shift from an industrial to a service- and then a knowledge-dominated economy has meant that employment is less predictable and dependable (Kelly and Moen 2007a, b; Moen and Roehling 2005; Elder et al. 2003). Over the past 10 years, employment has increasingly become more fluid, where individuals may have multiple careers and there is flexibility in relation to where, when and how work is performed (Chung and Pak 2021; Tomlinson et al. 2018). This has resulted in careers becoming fragmented and roles blurred between work and family life (Rofcanin and Anand 2020). These destandardised conditions (Kohli 2007) require flexibility in relation to the norms as to how individuals navigate their lives but also demands flexible working conditions that allow them to do so (Beck 1992; Hochschild 1997; Castells 2010; Rofcanin and Anand 2020).

There has been a steady increase in the number of employees in pursuit of flexible work in order to gain greater autonomy in deciding when, for how long and where they work (Korunka 2021). A core benefit of FWA is that it permits individuals to work outside the standard 9-5 workday (Lambert et al. 2008; De Menezes and Kelliher 2017). FWA has a spatial (e.g., working from home), temporal (part-time, flexible working hours) and contractual dimension (e.g., work benefits) (Walby 2011). This opens up opportunities for a wider range of individuals to enter employment who may have been constrained by inflexible working 
times and formats such as females or those with caring responsibilities (Chung and van der Lippe 2020). FWA has been suggested to be a key feature of a new form of work that restructures the standardised ways in which family and work roles interlock (Korunka 2021). The underlying assumption is that flexibility can alleviate the constraints that standardised working hours presents upon an individual's private life. This may then lead to greater increase work-life quality, and increased the opportunities to achieve gender equity for men and women, both at work and at home (Moen 2015; Chung and van der Lippe 2020). On the other side of the coin, research suggests that FWA can lead to the work sphere blurring and transgressing the boundaries of work and private life (De Menezer and Kelliher 2011; Korunka 2021). FWA enables, but also requires individuals to respond to multiple role demands which can in fact increase workloads (Allen et al. 2013; Cooper and Baird 2015; Langner 2017).

Overall, the realities of FWA is that the potential for flexibility, unfolds slowly. This has been suggested to be due to what Riley et al. (1994) describe as 'structural lag', where there is a lack of fit between employees' aspirations for FWA and the institutional and organisational structures, which may lag behind to allow potential benefits to be realised. For example, an organization may offer flexible work arrangements as a mechanism to aid gender equality in the workplace, however, the distribution of childcare responsibilities may still be following traditional gender stereotypes (Chung and van der Lippe, 2020). Similarly, changes in economic and technological conditions mean that remote working is possible in many sectors, however, some organizational cultures may still follow a path dependent trajectory, which values employees being present in the office. Furthermore, public work policies in central European welfare regimes are often tailored to gainful long-term employment and the two-person career limiting opportunities to take advantage of FWA. The inertness of institutions can cause a lag between potential action and structure; which can send mixed signals to individuals trying to navigate their working lives (Hari 2017; Moen and Orrange 2002). Moen $(2015,2016)$ suggest that a structural lag can operate at three levels: (1) public, social and labour market policies; (2) organisational policies and practices; and (3) individual/household strategies to cope with lagging policies and practices. She argues this structural lag largely induces contemporary gender inequality, which accumulates over the life course.

Family and work scholars largely agree that this structural lag stands in the way of realising the full potential of FWA. Whilst working conditions have indeed become more flexible over the past decades (Kossek and Lautsch 2017), access to FWA in many sectors is subject to individual negotiations instead of being part of a general policy (Kelly and Moen 2007a, b; Munsch et al. 2014), and is granted only to certain subgroups (Golden 2001; Kim and Gong 2016) or within specific industries (Walby 2011). In addition, a growing number of studies show that even when policies granting FWA are in place, certain organisational structures (e.g., rigid work hours; see Moen 2015) and cultures (e.g., face-time-oriented culture, see Shockley and Allan 2010) undermine their actual use (Allen et al. 2013). Or FWA is used in addition to regular presence in jobs and requires employees to be never off and always available, which results in overload, both in terms of work load and role overload (Kelly and Moen 2020). 
We suggest that the institutional and organisational constraints identified in the literature have also prevented empirical studies exploring the consequences of increased and unrestrained flexibility of work. Indeed, differentiated organisational contexts will present conditions impacting FWA implementation and outcomes. However, without testing these consequences, the assumed links between access to FWA, its use and impact on gender equality at work and at home remain hypothetical. This has limited the development of literature on FWA. In order to explore this concept and test assumed relationships between core concepts, there is a need to identify a working environment in which FWAs are actually used under conditions marked by reduced institutional and organisational constraints, in order to develop theory regarding the consequences of FWA use. Drawing on the perspective of a sociological theory of the life course, we suggest that family businesses in Germany represent a context which can present favourable conditions for FWA use-at least for family members who own and work in that business as managers and employees.

\subsection{Working in one's family business as context with favourable boundary conditions}

Traditionally, a family business can be defined loosely as a business which is owned or run by family members (Chua et al. 1999; Rovelli et al. 2021). For the purpose of our research we are interested in family businesses as particular working context, however, we are not focused on everyone working in that business, but are interested in employees who are members of the owing family. They may work in their family's business as self-employed, employed managers, employees or interns. Their working conditions are distinct from a regular employment context, due to them being related to the business owners or are the owners themselves. In this research we will relate to this specific group as family members working in their family's business (FB).

We argue that that family businesses may be naturally conducive to the blending of work and family. Therefore, this may result in a reduced structural lag at the individual level for family members who are working in their family's business. Furthermore, at the organizational level, it could be suggested that family members are involved in entrepreneurial work, which grants them a high degree of autonomy and consequently may be more conducive to FWA.

\subsubsection{Reduced structural lag on individual/household level}

The sociological theory of the life course suggests that within business families, the blending of work and family spheres is a natural condition rather than the result of a de-standardisation process (Kohli 2007). The business provides income and wealth to the family, offers career options to family members and is a central element of their social identity (Stamm 2016). Research by King and Elder (1995) found that in business families, "work and family roles are interwoven in social and physical space" (p. 165). Hence, in these families, roles that are typically thought of as separate, often overlap (Gersick et al. 1997), creating a situation that requires continuous 
boundary definition. These structural conditions of business families create potential flexibility, especially for those family members actively working in their family's business.

Potential flexibility is a permanent state in business families rather than a lifecourse episode. Work scholars have repeatedly suggested that in regular employment, FWA becomes desirable during particular life phases, such as parenthood or when caring for elderly parents (Blair-Loy 2010; Golden 2001). In business families, the demand for FWA extends over the entire life course (from volunteer helper, to family employee, to owner-manager), creating various forms of overlap between family and work; demanding flexibility in coping with that overlap. However, the structural conditions making flexibility potentially available do not automatically translate into FWA use. The next section examines typical organisational constraints and how they may or may not apply to the family business as a working environment for family members.

\subsubsection{Reduced structural lag on an organisational level}

Several work scholars have suggested that the most dominant organisational barrier to using FWA is employees' fear of being stigmatised as underperforming, which threatens to have negative consequences for career development (Glass 2004; Korunka 2021). Other challenges to effective implementation of FWA are a strong face-time-oriented culture among colleagues (Shockley and Allan 2010; van der Lippe and Lippényi 2020), a lack of first-movers to adopt FWA among immediate co-workers (Lambert et al. 2008), a need to request FWA use personally (Cooper and Baird 2015), and supervisors who are inexperienced in the use of FWA (Munsch et al. 2014). It has been found that supervisors who are supportive of family affairs can positively influence FWA use (Bagger and Li 2014; Beigi et al. 2018).

As mentioned previously, family members working in their family business may be in a distinct position, either due to their occupational status as head of the business or their family status as parent, spouse, child or other relative of the head of the business, to avail of FWA. Therefore, we suggest that occupational and family status may create an environment favourable to more frequent FWA use.

Occupational status: Family members regularly engage either directly or indirectly in tasks related to owning and/or managing the business. In this position, they perform entrepreneurial work, which includes a bundle of activities targeted toward the creation or operation of a business venture (Shane and Venkataraman 2000). Entrepreneurial work typically entails a high degree of work autonomy (Freidson 1984), albeit directly dependent upon their stakeholders' interests and market developments (Teoh et al. 2016). Even without direct ownership in the business, family members' greater autonomy in their entrepreneurial work regularly translates into psychological ownership (Bernhard and O'Driscoll 2011). In their considerations as to whether to use FWA, psychological owners do not have to fear potential career setbacks or the disapproval of a supervisor or external investors, but they do have to consider whether FWA use is appropriate to achieve their family and business objectives. The work autonomy associated with entrepreneurial work, in particular the work flexibility which can be achieved, has made self-employment and business 
ownership particularly attractive for women (Yang and Aldrich 2014; Chung and van der Lippe 2020).

Family status: Family members often can avail of opportunities for employment in their family's business (this includes occasional work and permanent positions in all areas of a business). Family employees are similar to individuals working in regular employment in terms of the type of work they perform, yet they are in a strong tie relationship to a business owner which can lead to benefits and challenges. Such conditions allow them to be with or close to a family member while at work, which can lead to role overlap between family and work life; but also reduce role conflict (Cooper et al. 2013; Houshmand et al. 2017). Such conditions also provide additional incentives to grant and use FWA, as this flexibility may be beneficial to the family running the business (Dreyer and Busch 2021). For example, allowing a family member to leave early and continue work later from home, may benefit the caretaking of one's own children. Working in one's family's business potentially grants family employees nepotistic privileges in working conditions and will most likely be associated with a family-supportive supervisor (Ferraro and Marrone 2016).

We argue that all family members working in their family's business share access to work flexibility due to their occupational and familial status. This is a key feature of business families across the wide array of business sizes and different fields and regions in which they operate (Rothausen 2009). Given these particularities, we suggest that the enhanced autonomy granted through entrepreneurial work and nepotism potentially reduces organisational constraints on FWA use.

\subsubsection{Reduced structural lag on public policy level}

We suggest that Germany represents a context which is seeking to reduce the structural lag at the institutional level in matters relating to both gender equality and importance of family businesses for the economy. First, whilst Germany has a strong tradition of the male-breadwinner-female homemaker model (Leitner 2004); in recent years, there have been strong calls for gender equality. Therefore, FWA has become an emblem of a modern and privileged working environment in Germany over the past two decades (Almendinger 2021). Policymakers and businesses alike have hastily pursued the creation of flexible working conditions, with the media vividly documenting their efforts. The German government and federal states have implemented several measures to improve the working conditions for women and employees with families (Fagnani 2012; König and Cesinger 2015; Langner 2017). In parallel, the public and management discourse often promotes flexibility in the workplace, not only implying that it is a way to increase gender equality but that is can also alleviate challenges associated with a shrinking and ageing workforce (Fagnani 2012; Grunow et al. 2006). In this context, organisations are not only inclined to offer flexible work policies, but individuals are also prone to use FWA. Despite these public policies, gender inequality at the workplace and strong gendered consequences of FWA use persist (Allmendinger 2021). Second, family businesses play a crucial role in the German economic system, as they control the vast majority of all businesses and employ about half of 
the German workforce (Gottschalk and Keese 2011). In sum, we put forth the following baseline hypothesis on the use of FWA in German business families derived from a sociological theory of the life course:

Hypothesis 1 (H1) Family members working in their family's business will be more likely to engage in FWA than employees in regular employment.

\subsection{Exploring the consequences of higher FWA use}

If $\mathrm{H} 1$ holds true, and family members working in their family's business actually do make more frequent use of FWA than employees in regular employment, working in one's family's business should be an ideal setting to observe and test a number of assumed effects of FWA. A common belief is that more FWA use would allow men and women to engage more equally in work- and family-related tasks (Moen 2015; Langner 2017; Wheatley 2017). Therefore, in the following sections, we derive a hypothesis on workload and the division of work at home for the context of family member employees working in their family's business.

\subsubsection{Workload}

Numerous studies have documented a substantially higher workload for selfemployed individuals compared to those in regular employment (Teoh et al. 2016). In particular, entrepreneurial work, which is not restricted by contractual working hours, is associated with high work demands and a potential shortage of resources to meet these demands (Matta 2015). Family members working in their business often engage in entrepreneurial work and thus may face longer working hours (Teoh et al. 2016). Studies have illustrated how having control over one's own work schedule extends and intensifies working hours (Matta 2015; Langner 2017). At the same time, family employees may feel indebted to the hiring family member (Jaskiewicz et al. 2013) and want to prove their merit to family members and co-workers by working more. Furthermore, an increase in FWA use among family business members (see H1) could be suggested to enable women to participate in full-time employment, driving up their hours. For example, Dinh et al. (2017) have shown that flexible working conditions and support structures can encourage women to work full-time. While this effect can be associated with increased overall pressure and stress, it can also be a desirable opportunity for female entrepreneurs who seek to balance career aspirations with family demands (Loscocco and Bird 2012). Hence, we expect a spiral effect in which family members work more because they have easier access to and thus make more frequent use of FWA while, conversely, they need to make more use of FWA since they work more.

Hypothesis $2(\mathrm{H} 2)$ Family members working in their family's business will have longer weekly working hours than employees in regular employment. 


\subsubsection{Gender equality}

Flexible work is thought to allow an easier reconciliation of work and family related tasks and thus increases work-life-balance (Chung and van der Lippe 2020). In this sense, flexible working can be a useful tool to further enhance gender equality in our societies. However, Lott and Chung (2016) caution that society's pre-existing views on gender roles and gender normative views towards men and women's roles and responsibilities, can result in FWA potentially further traditionalising gender roles in the labour market and the household. In an entrepreneurial context, it is a wellevidenced phenomenon that women in entrepreneurial positions integrate work and family responsibilities, whereas male entrepreneurs more strongly rely on support from home (Hundley 2000; Loscocco and Bird 2012; Eddleston and Powell 2012). Similarly, Haynes et al. (1999) show that if the household manager works in a family business, they still organise childcare in the same way as in situations where the household manager does not work-in other words, in both scenarios, childcare is often organised within the family and by women. Hilbrecht and Lero (2014) find that self-employed parents mostly follow traditional gender role patterns, although they also suggest that fathers see self-employment as a way to participate more actively in family life. Following Kelly and Moen (2020), these tendencies can lead to an acute problem of role-overload for family member employees working within family businesses.

Surprisingly, very few studies to date take a comparative perspective of entrepreneurial and regular working contexts but instead compare men and women within a specific setting (Wheatley 2017). Therefore, much remains unknown on whether the suggested and still unequal distribution of paid and unpaid work in business family contexts measures up against a regular employment context. In line with the argumentation above, we suggest that families who work in their own businesses are working in a setting that is structurally conducive to flexibility and have fewer organisational constraints for FWA. Consequently, since FWAs are structurally more easily available in this context, this makes the division of paid and unpaid labour more a matter of direct negotiation between spouses (Lyonette and Crompton 2015). Hence, despite the reported uneven distribution of tasks, we hypothesize an interpretation of the business family context as being a means of emancipation or empowerment that allows individuals to reconcile their careers and family responsibilities (Pines et al. 2010). This leads to our third and final hypothesis.

Hypothesis 3 (H3) Family members working in their family's business will share their paid and unpaid work more equally with their partners than employees in regular employment. 


\section{Method}

\subsection{Data and sample}

In order to test our hypotheses, we utilised data from the fifth wave of the German Family Panel (PAIRFAM). This survey is representative of all people living in private households in Germany who were born within one of three birth cohorts: 1971-1973, 1981-1983 and 1991-1993 (Huinink et al. 2011). In its fifth wave (2012-2013) PAIRFAM covered 7248 participants. We identified family members working in their family's business by their ownership, job and kinship status (Stamm et al. 2019). We selected respondents who work in a business that either they or a family member own or co-own. This included self-employment, leading management positions or other types of employment (e.g., accounting, an apprenticeship).

We identified 337 respondents who met our criteria of a family member working in their family's business. Among them, we differentiated two subgroups according to their ownership-work relation, namely owner-manager and family employees.

Owner-manager: This subgroup consists of 195 individuals who are selfemployed or in leading management positions in the business that they (co-)own and who employ their spouse/partner, members of their family or members of their spouse's/partner's family. Among this group, occupational status in the business is the main source of higher flexibility.

Family employees: This subgroup consists of 142 respondents who work in a business that is owned by their spouse/partner, other family members or family members of their spouse/partner. Among this group, their status as a member of the family that owns the business is the main source of higher flexibility.

The total sample included heterogenous individuals holding various positions within a family business such as self-employed craftsmen, managing owners of a medium-sized industrial company, spouses involved in bookkeeping or children doing an apprenticeship in their parents' business. Respondents were heterogeneous in terms of household composition, marital status and business involvement. To be included in the sample, it was not a precondition, though possible, to live in the same household as the person involved in the family business or to be married to that person.

\subsection{Developing the control group via propensity score matching}

To understand the use of FWA and its consequences in different organisational working environments, our analytical strategy was to compare individuals working in their family's business (FB) to those with similar characteristics but working in regular employment (RE). To construct this regular employment control group (Morgan and Harding 2006), we undertook several steps. First, from the large number of non-FB respondents in our original data set, we eliminated all respondents who were unemployed, for whom data was missing concerning their job activities, or who were freelancers or academic professionals. This resulted in a non-FB group which was much more heterogeneous but still six times larger than the FB group. 
Comparing these groups would create biased variance in FWA use, as it is likely that some individual factors not only correlate with FWA but are already specific to the FB group - for example, some industries or occupations might have a higher prevalence of family businesses and therefore offer more FWA. In other words, this type of sample would result in a selection bias that increases individuals' likelihood of becoming a member of the FB group in the first place (Rosenbaum and Rubin 1984). To offset this potential bias and to develop an appropriate control group, we followed the examples of others facing this issue (Choi et al. 2015; Neckebrouck et al. 2018) and used Rosenbaum and Rubin's (1984) propensity-based matched pair design as the principal method. To achieve this, we first identified variables that influence the likelihood of working in one's family's business and second only included non-FB individuals in the RE group who are most similar in terms of these characteristics. A literature review of factors that increase the likelihood of being a business family helped us identify key correlations. It was suggested that the familial opportunity structure and socialisation and the individual's life and occupational experiences, largely determine the diverse pathways to business ownership or working in one's family's business (Lofstrom et al. 2014; Jennings et al. 2013; Schröder and Schmitt-Rodermund 2013). We identified and included adequate measures for each of these 'FB factors' in our data. These were, occupation (ISCO, four digits), age, gender, relative location (East vs. West Germany), regional density, respondent's vocational or technical training, respondent's migration status and the vocational training of the respondent's father and mother.

We used logistic regression models to estimate each respondent's 'propensity score', that is, the probability of working in one's family's business given the individual's specific combination of 'FB factors'. For each respondent working in their family's business, we selected one individual in regular employment with the most similar propensity score, resulting in 337 matched pairs. Propensity score matching generates a vector score, using a specified set of covariates for each observation, and then matches it with the closest scoring observation in the respective subset (Rosenbaum and Rubin 1984). The method lowers influence of unobserved heterogeneity, lowers Type 1 error, and provides more conservative estimates than regressions (Dehajia and Wahba 2002). However, a shortcoming of the propensity-score matching approach is that it strongly relies on observable characteristics and assumes that non-unobservable characteristics affecting the outcome differ systematically between the two groups (Bertoni et al. 2019). Following Choi and Colleagues (2015), we matched employees in a regular employment context to FB (Family Business context) individuals, applying the one-toone nearest neighbour algorithm with a caliper of 0.1 . As a robustness check, we did sensitivity analyses (Rosenbaum 2002; Caliendo and Kopeinig 2005). Applying Becker and Caliendo's (2007) procedure, we found that the results were robust to unobserved heterogeneity in the matching procedure. Tables 2, 3, 4 and 5 in the appendix present descriptive statistics on the FB and RE groups prior to and after the matching procedure. These statistics confirm that the propensityscore matching procedure did indeed yield a group of individuals working in a regular employment context that largely resemble their FB counterparts. Table 6 reports the verbatim wording of all items included in our analysis. 


\subsection{Multivariate analysis of FWA use and its consequences}

We applied multivariate regression models to test our hypotheses. For H1, we analysed the relationship between work environment and reported FWA use. Previous research has provided evidence that the use of various forms of FWA (e.g., flexible working hours, control over one's work schedule, home office) is associated with different user groups and reasons. Hence, we looked at the temporal and spatial dimensions of flexibility separately (Allen et al. 2013; Wheatley 2017). The dependent variables are flex-time (i.e., a work schedule without any time regulation) in model M1 and flex-place (i.e., a flexible workplace such as a home-office option) in M2 (see Table 2).

To test $\mathrm{H} 2$, the dependent variable was workload (see M3), as measured by the reported total number of paid weekly working hours including overtime. We controlled for both FWA-use indicators (i.e., flex-time and flex-place) and also included the respondent's partner's workload on the grounds that this partner's time budget can be expected to affect the respondent's decision to work longer or shorter hours (Lyonette and Crompton 2015).

Finally, we analysed the influence of working in one's family's business on the division of household labour in order to test H3. Following the existing literature, we used the self-reported distribution of housework tasks (M4) as well as respondents' subjective evaluations of equality (M5). For all models, we ran additional analyses comparing both FB subgroups (owner-managers and family employees) to REs and performed robustness checks (see Appendix).

\section{Results}

\subsection{Characteristics of the FB and RE groups}

Through the matching procedure, we were able to create a comparison group that has similar socio-demographic characteristics to the business families which were surveyed. In both groups, women were slightly underrepresented (44.2\% in RE, $43.0 \%$ in FB). The mean age was around 34 years, the majority of respondents lived in a relationship and had minors living in their household. Mean monthly net equivalence income was $€ 1787$ for RE and $€ 2040$ for FB respondents. More than $80 \%$ of respondents in both groups had no migration history, about a quarter lived in bigger cities, approximately $40 \%$ had completed vocational training and a minority $(10.1 \%$ of RE respondents, 7.7\% of FB respondents) had a university degree. Occupations were similarly diverse in both groups, ranging from shop sales assistants (8.9\% of RE 7.4\% of FB respondents) through general office clerks (3.3\% versus $4.2 \%$ ) to secretaries (4.5\% and $2.7 \%$, respectively). With regard to job status, the majority of RE respondents (30.9\%) reported being employees with qualified duties, whereas most FB respondents (38.5\%) were 'other' self-employed (i.e., not farmers or academic professionals) with one to nine employees. The descriptive statistics confirm that we were indeed comparing family members who own and run small- and medium-sized businesses with those who do similar work (e.g., work as an office clerk or manager) in regular employment. 
When considering the actual use of FWA and the consequences of such use, we found large differences between both groups. In the following, we present our descriptive and multivariate findings on FWA use, workload and gender equality. Table 1 depicts the results of our models. Column A refers to a comparison between FB and RE, while column B refers to a differentiated comparison of FB types (owner-managers and family employees) with those in regular employment.

\subsection{Higher FWA use among family members in their family's business}

We found that FB respondents made more frequent use of FWA when it came to flexible working hours and a home-office option. $44.2 \%$ of all FB respondents had a flexible or no set time schedule compared to $8.6 \%$ of the matched RE types (see Table 2). FB respondents also had more flexibility in terms of where they worked, where it was found that $21.5 \%$ of FB respondents worked from home to some extent and $8.7 \%$ entirely, compared with $9.5 \%$ of the RE respondents partly working from home and $0.9 \%$ doing so entirely. The analysis showed that the probability of using flexible time arrangements was 5.6 times higher for FB respondents than for RE respondents. We further found a significant effect of working in one's family's business on making use of flexible workplace arrangements. These results confirm H1.

\subsection{Higher workload only for owner-managers}

H2 predicted longer working hours for family members working in family businesses. On average, FB respondents reported working for $42.62 \mathrm{~h}$ per week, which is $5.38 \mathrm{~h}$ longer than RE respondents. $42.4 \%$ of $\mathrm{FB}$ respondents worked overtime compared to just $16.2 \%$ of RE respondents, while the majority of the latter $(57 \%$ compared to $31.5 \%$ of FB respondents) stayed within the time frame of a full-time employment contract. The differences are statistically significant and support $\mathrm{H} 2$. When we examined the different groupings within the FB population compared to the RE respondents, we found that higher work flexibility went along with a higher workload only for owner-managers. Family employees did not differ significantly from regular employment in terms of workload. In addition, we found a pronounced gender effect across the complete sample: regardless of belonging to the FB or RE group, on average, men in our sample worked $12 \mathrm{~h}$ a week longer than women.

\subsection{Unequal but fair}

We found that FB and RE groups distribute housework unequally between men and women. The results identified that women handle more of the household chores than their partners, which was even more prominent in male bread-winner constellations. Descriptive statistics suggest that this division of household labour is less equal in the FB group, where it was found that $28.6 \%$ of RE reported that housework is split equally in comparison to only $19.1 \%$ of FB respondents. Our regression analysis showed that this difference is statistically non-significant; which is counter to our expectations. 
Table 1 Results of multivariate regression models (M)

\begin{tabular}{|c|c|c|c|c|c|c|}
\hline & \multicolumn{4}{|l|}{ FWA } & \multirow{2}{*}{\multicolumn{2}{|c|}{$\frac{\text { Workload }}{\text { M3 workload (H2) }}$}} \\
\hline & \multicolumn{2}{|c|}{ M1 flex-time } & \multicolumn{2}{|c|}{ M2 flex-place } & & \\
\hline & $\mathrm{A}(\mathrm{OR})$ & $\mathrm{B}(\mathrm{OR})$ & $\mathrm{A}(\mathrm{OR})$ & B (OR) & A (coef.) & $\begin{array}{l}\text { B (coef.) } \\
\text { (Coef }\end{array}$ \\
\hline $\mathrm{FB}^{\mathrm{a}}$ & $5.6^{* * * *}$ & & $2.3 * * *$ & & $3.3 * * *$ & \\
\hline FB owner-manager ${ }^{a}$ & & $7.6^{* *}$ & & $2.5^{* *}$ & & $6.09 * *$ \\
\hline FB family employee ${ }^{a}$ & & $3.4 * *$ & & $2.2^{*}$ & & 0.3 \\
\hline \multicolumn{7}{|l|}{ Covariates } \\
\hline Women $^{\mathrm{b}}$ & 0.6 & 0.6 & 1.5 & 1.5 & $-11.7 * * *$ & $-11.5^{* *}$ \\
\hline \multicolumn{7}{|l|}{ Workload respondent ${ }^{\mathrm{c}}$} \\
\hline $1-14 \mathrm{~h}$ per week & 0.7 & 0.8 & 1.1 & 1.1 & & \\
\hline $15-24 \mathrm{~h}$ per week & 1.0 & 1.0 & 0.7 & 0.8 & & \\
\hline $25-34 \mathrm{~h}$ per week & 0.5 & 0.5 & 0.6 & 0.6 & & \\
\hline $50+$ hours per week & $4.3 * * *$ & $3.9 * *$ & 1.6 & 1.5 & & \\
\hline \multicolumn{7}{|l|}{ Workload partner ${ }^{c}$} \\
\hline $1-14$ h per week & & & & & 4.3 & 4.9 \\
\hline $15-24 \mathrm{~h}$ per week & & & & & $8.2 * *$ & $8.4^{* *}$ \\
\hline 25-34 h per week & & & & & 4.9 & $4.9 *$ \\
\hline $50+$ hours per week & & & & & 1.3 & 2.1 \\
\hline Commuting daily $^{\mathrm{d}}$ & $0.3 * * *$ & $0.3 * *$ & 1.0 & 1.0 & & \\
\hline Job importance & & & & & $1.0 * *$ & $0.9 * *$ \\
\hline Flex-time & & & & & $3.9 * *$ & $3.9 * *$ \\
\hline Flex-place & & & & & $3.2 *$ & $3.2^{*}$ \\
\hline \multicolumn{7}{|l|}{ Controls ${ }^{\mathrm{e}}$} \\
\hline Net equivalence income & 1.0 & 1.0 & 1.0 & 1.0 & 0.0 & 0.0 \\
\hline $\operatorname{Kid}(\mathrm{s})$ in household & 0.9 & 0.9 & 1.1 & 1.1 & $-5.6 * * *$ & $-5.6^{* * *}$ \\
\hline Age & 1.0 & 1.0 & 1.0 & 1.0 & $0.3 * * *$ & $0.3 * * *$ \\
\hline Constant & $0.2 * * *$ & $0.2 * *$ & $0.1 * * *$ & $0.1 * * *$ & $41.2 * * *$ & $41.2 * * *$ \\
\hline Pseudo-/adjusted $\mathrm{R}^{2}$ & 0.25 & 0.26 & 0.05 & 0.05 & 0.28 & 0.28 \\
\hline $\mathrm{N}$ & 560 & 560 & 560 & 560 & 591 & 591 \\
\hline LR Chi2 & $151.23 * * *$ & $158.23 * * *$ & $25.75^{* * *}$ & $25.87 * * *$ & & \\
\hline $\mathrm{F}$ & & & & & $17.23 * * *$ & $17.49 * * *$ \\
\hline Mean VIF & 1.56 & 1.52 & 1.56 & 1.52 & 1.80 & 1.76 \\
\hline \multirow[t]{4}{*}{ Max VIF } & 2.06 & 2.06 & 2.06 & 2.06 & 2.34 & 2.35 \\
\hline & \multicolumn{6}{|c|}{ Gender equality } \\
\hline & \multicolumn{4}{|c|}{ M4 equality-duty (H3) } & \multicolumn{2}{|c|}{ M5 equality-fairness (H3) } \\
\hline & \multicolumn{2}{|l|}{ A (OR) } & \multicolumn{2}{|c|}{ B (OR) } & A (OR) & B (OR) \\
\hline $\mathrm{FB}^{\mathrm{a}}$ & \multicolumn{2}{|l|}{1.4} & \multicolumn{4}{|c|}{$0.3^{* *}$} \\
\hline FB owner-manager ${ }^{\mathrm{a}}$ & & & \multicolumn{2}{|c|}{1.4} & \multicolumn{2}{|r|}{0.5} \\
\hline FB family employee ${ }^{a}$ & & & \multicolumn{2}{|c|}{1.5} & & $0.2 * *$ \\
\hline Covariates & & & & & & \\
\hline
\end{tabular}


Table 1 (continued)

\begin{tabular}{|c|c|c|c|c|c|}
\hline & \multicolumn{5}{|c|}{ Gender equality } \\
\hline & \multicolumn{3}{|c|}{ M4 equality-duty (H3) } & \multicolumn{2}{|c|}{ M5 equality-fairness (H3) } \\
\hline & \multicolumn{2}{|l|}{ A (OR) } & B (OR) & $\mathrm{A}(\mathrm{OR})$ & $\mathrm{B}(\mathrm{OR})$ \\
\hline Women $^{\mathrm{b}}$ & \multicolumn{2}{|l|}{$61.4 * * *$} & $60.6 * * *$ & 2.1 & 2.2 \\
\hline \multicolumn{6}{|l|}{ Workload combination ${ }^{\mathrm{f}}$} \\
\hline Part-timers & \multicolumn{2}{|l|}{$30.9 * *$} & $31.2 * *$ & 0.9 & 0.1 \\
\hline Dual career & \multicolumn{2}{|l|}{$4.4^{*}$} & $4.4^{*}$ & $0.1^{*}$ & $0.1^{* *}$ \\
\hline Traditional partner & \multicolumn{2}{|l|}{$23.5 * * *$} & $23.4 * * *$ & $0.1 * *$ & $0.1^{* *}$ \\
\hline Flex-time & \multicolumn{2}{|l|}{1.7} & 1.7 & & 0.7 \\
\hline Flex-place & \multicolumn{2}{|l|}{0.8} & 0.8 & & 1.2 \\
\hline \multicolumn{6}{|l|}{ Distribution of housework ${ }^{\mathrm{g}}$} \\
\hline Respondent does most & & & & $11.2^{* * *}$ & $11.9 * *$ \\
\hline Partner does most & & & & 0.9 & 0.9 \\
\hline \multicolumn{6}{|l|}{ Distribution of child care ${ }^{\mathrm{g}}$} \\
\hline Respondent does most & & & & $3.2^{* *}$ & $3.4^{* *}$ \\
\hline Partner does most & & & & 0.3 & 0.3 \\
\hline \multicolumn{6}{|l|}{ Controls $\mathrm{e}$} \\
\hline Net equivalence income & \multicolumn{2}{|l|}{1.0} & 1.0 & 1.0 & 1.0 \\
\hline Kid(s) in household & \multicolumn{2}{|l|}{$3.3^{*}$} & $3.3^{*}$ & & \\
\hline Age & \multicolumn{2}{|l|}{1.03} & 1.03 & 1.0 & 1.0 \\
\hline Constant & \multicolumn{2}{|l|}{$0.0 * * *$} & $0.0 * * *$ & 0.2 & 0.3 \\
\hline Pseudo $\mathrm{R}^{2}$ & \multicolumn{2}{|l|}{0.61} & 0.61 & 0.27 & 0.28 \\
\hline $\mathrm{N}$ & \multicolumn{2}{|l|}{371} & 371 & 293 & 293 \\
\hline LR Chi2 & $292.30 * * *$ & $292.32 * * *$ & $75.40 * * *$ & $77.02 * * *$ & $292.30 * * *$ \\
\hline \multicolumn{6}{|l|}{$\mathrm{F}$} \\
\hline Mean VIF & 1.92 & 1.85 & 3.44 & 2.89 & 1.92 \\
\hline Max VIF & 3.43 & 3.46 & 6.85 & 6.84 & 3.43 \\
\hline
\end{tabular}

Models 1, 2, 4, and 5 are logistic regressions, reporting unstandardized odds ratios (OR). Model 3 is a linear regression model, reporting regression coefficients (coef.). Reference categories: ${ }^{\mathrm{a}} \mathrm{RE},{ }^{\mathrm{b}} \mathrm{man},{ }^{\mathrm{c}}$ fulltime, ${ }^{\mathrm{d}}$ no or less than daily commuting; ${ }^{\mathrm{e}}$ means-centred, ${ }^{\mathrm{f}}$ traditional respondent, ${ }^{\mathrm{g}}$ about half/half. Significance levels: ${ }^{*} p<0.05, * * p<0.01, * * * p<0.001$. Source PAIRFAM release 5.0, our own calculations

However, we did find that more FB respondents reported that they perceive the division of paid and unpaid labour within their partnership as fair compared to RE $(78.2 \%$ FB vs. $66.8 \%$ RE). Our regression analysis shows that FB respondents are less likely to perceive the (unequal) division of household labour as being unfair than RE respondents. Family employees were particularly likely to report that they do not do more than their fair share around the house. Overall, our findings provide a more nuanced view on the hypothesised relationship between working in the family's business and gender equality. While the actual division of household labour (in hours) does not confirm more gender equality, the analysis of respondents' perceived fairness of labour division supported H3. 


\section{Discussion}

For long, flexibility has been promoted as key feature of a redesigned form of work, compatible with contemporary ideas of gender equality (Chung and van der Lippe 2018; Gerards et al. 2021; Korunka 2021). However, empirical research to date yields mixed results on the effects of flexibility. On the upside, flexible work arrangements (FWAs) build the foundation for reduced work-family conflicts, increased satisfaction and a range of positive attitudes at work (Bagger and Li 2014; Lapierre and Allen 2012). These positive benefits are not only valued by family business leaders and human resource professionals, but policy makers in Germany have a vested interest in enhancing the sustainability and performance of family firms. However, on the downside, role blurring may also lead to additional stress and work-life conflict (Jung Jang et al. 2012; Schieman and Glavin 2016) as well as role-overload (Kelly and Moen 2020). In order to explore this conundrum, there is a need to understand and distinguish whether FWA has been implemented and if it has been implemented, has it actually been used. Therefore, we utilized a family business context, as a way of being sensitive to the factors constraining actual FWA use; where this context also allows for exploration into in the benefits and consequences of FWA.

From our findings, we show that family members working in their family's business make significantly more use of flexible time and working place arrangements than employees in regular employment. In particular, the use of flexible time arrangements was much more frequent than the use of flexible place arrangements, especially among owner-managers. Owner-managers were found to significantly utilise FWA, which expands research by Lambert et al. (2008) who suggests that those with supervisory responsibilities are more likely to make use of FWA. In addition, our findings show that family employees working in a family business also use flexible time arrangements significantly more often than RE. This indicates that family status is indeed an important source of flexibility alongside occupational status. Therefore, we provide new knowledge by suggesting that nepotistic privileges and close ties to the owners and decision-makers (Jaskiewicz et al. 2013) are relevant factors which are conducive to FWA. These factors have been overlooked in research to date.

Prior research suggests that in most companies, even when policies granting FWA are in place, certain organisational structures (e.g., rigid work hours; see Moen 2015) and cultures (e.g., face-time-oriented culture, see Shockley and Allan 2010) undermine their actual use (Allen et al. 2013). Therefore, limited studies to date have investigated the effects of a FWA policy which can be freely chosen by employees. It was found that there were differences in flexibility between people working for their family business and those in regular employment. Through our findings, we argue that the 'family in business' setting can adequately serve for a broader study of the consequences of FWA use.

In relation to $\mathrm{H} 2$, we compared the practice of engaging in work and household tasks between regular employees (RE) and employees who are family members working in their family's business (FB). This was to explore if they encountered common assumptions which are often associated with high FWA use, such as work 
intensification (Chung and van der Lippe 2020). We found a significantly higher workload for FB respondents, which at first sight would support H2. However, when comparing family members in managerial positions with family employees, we found that only the owner-managers work longer hours. This suggests that there is no causal relationship between the use of FWA and a higher workload per se. Instead, the longer working hours appeared to be related to specific job demands (e.g., those of owners who manage their family business) as suggested previously by Matta (2015). this finding is consistent with prior research which suggests self-employed individuals and professionals can more prone to experience overwork (Kossek and Lautsch 2017; Annink et al. 2016) and that this is not necessarily related to FWAs. The findings also revealed a strong gender effect regarding workload. This extends research by Lott and Chung (2016) which shows that mostly men tend to use their flexibility gains to work more.

Our findings extend previous research on the complex relationship between gender equality and flexibility (Korunka 2021). Contrary to H3, we found an unequal distribution of household tasks between genders. The findings identified that women carry the double burden of gainful work and housework more frequently; even among FB respondents. In this regard, we did not find significant differences between FB and RE respondents. Therefore, we did not find support for the popular idea that making more frequent use of FWA translates directly into a more equal distribution of labour at work and at home (Moen 2015; Langner 2017; Wheatley 2017). Instead our findings support more recent research that detects overload as a consequence of FWA use (Kelly and Moen 2020).

FB respondents were less likely than RE respondents to consider the (unequal) distribution of labour as 'unfair'. This result is counterintuitive, as one would believe that FB respondents might suffer from greater (financial) dependence on other family members than RE respondents. However, it could be suggested that higher levels of perceived fairness may be the result of more flexible family business settings affording spouses greater scope to directly negotiate the distribution of both paid and unpaid work (Kelly and Moen 2007a, b). The FB respondents and their spouses are partners in a joint entrepreneurial endeavour-either through direct occupational engagement or by providing support. This interpretation feeds into existing theories in family business research that underscore how family employees can be psychological owners of the family business (Bernhard and O'Driscoll 2011; Bernhard 2011) and how justice perceptions can interact with the ownership experience (Sieger et al. 2011). We suggest that the engagement in a joint endeavour can result in higher perceived autonomy and control regarding one's individual contribution to the joint project. In turn, an increased sense of control may improve respondents' satisfaction and the perception that the distribution of work is fair (Lapierre and Allen 2012).

To explain increased perceived fairness in the light of continuing gender inequality, our findings indicate the relevance of structural factors such as relative availability of time (Correll et al. 2014) but also the role of agency in 'doing gender' (Lyonette and Crompton 2015). In an environment with reduced structural constraints, individuals are required to negotiate their roles directly and fall back on cultural scripts of gender norms to do so. Given that Germany provides the 
context to our study, we can assume that FB and RE respondents generally draw on similar pre-existing views of gender roles and norms. Recent research suggests that in Germany, the adherence to stereotypical gender roles is still quite common despite numerous policy efforts (Köppen and Trappe 2019). This can lead to the perpetuation of traditional gender roles, even among those who were using FWA (Lott and Chung 2016; Chung and van der Lippe 2020). Indeed, our findings suggest an unequal distribution of household tasks among those making high use of FWA. This finding was evident in recent events during Covid-19, where Almendinger (2021) found that a higher use of FWA relating to home office arrangements resulted in a more unequal distribution of tasks and a traditionalising of gender roles. Therefore, our findings suggest that FWA may lead to role overload and unequal gender roles in business family but still result in higher satisfaction relating to task distribution among couples.

\section{Conclusion}

This research set out to explore if individuals working in their family's business, work under favourable boundary conditions which enable them to more freely make use of and benefit from FWAs. With growing public awareness on the conditions and consequences of workplace flexibility, there is a need for current empirical evidence illustrating the determinants relating to FWA implementation and outcomes. Through a process of theory borrowing from sociological insights (Kushins and Behounek 2020), we theorized and tested how concepts relating to 'structural lag' may lead to differentiated consequences of FWA for FB and RE contexts. In doing so, we provide new knowledge related to FWA design, which helps advance literature on FWA and will be of benefit for managers and HR professionals who are seeking to implement flexible work arrangements. Overall, this study provides new insights on the assumed causal relationships between more work flexibility, work intensity and greater gender equality (Correll et al. 2014; Blair-Loy 2010; Kelly and Moen 2020). Consequently, our study has several contributions for theory and practice.

First, this study extends current family firm literature by providing a better understanding of the working conditions of individuals who work in their family's business. We provide new knowledge by identifying the heterogeneous ways FB individuals engage in their respective family business. We find that there are substantial differences regarding the benefits and outcomes of FWA between owner-managers and family employees. Whilst both make extensive use of FWA, this resulted in a larger workload and risk of overwork for owner-managers but not for family employees. Our findings suggest that work and role demands play a crucial role in explaining workload consequences of FWA.

Second, we extend current literature on the benefits and consequences of FWA through providing nuanced knowledge of the conditions under which FWA should be used. We identify the importance of organisational and socio-relational factors in determining FWA outcomes. The findings illustrate that family members' specific status within the organisation allowed for greater flexibility in reconciling work and family duties, which in turn translates into more FWA use. Our findings 
further suggest that there may be various factors contributing to flexibility privileges in organisations. We provide new knowledge on the importance of occupational and familial relations for FWA. We identify that it is not only the job or the business which determines the capacity to be flexible but that worker's relationships with others in the organisations influences FWA outcomes. This goes beyond supervisor-worker relationships, which have been studied in FWA literature, and suggests an important boundary condition to theories on FWA. Understanding that flexibility in family businesses is differentiated to regular employment practices is important, particularly when these form of organization presents the majority of businesses worldwide (Astrachan and Shanker 2003).

Third, our study offers a better understanding on the assumed relationships between flexibility, workload and gender equality in a sociology of the life course. By separating out owner-managers from family business employees, we show that higher use of FWA can go along with greater workload. In contrast, non-managing family members do not have to work longer in spite their higher level of flexibility. Furthermore, our findings suggest that abundant flexibility for family members in businesses fails to create gender equality. However, the findings identified that the perception of fairness increases when implementing FWA- even under conditions indicating unequal distribution of labour. Consequently, our findings suggest that previous studies might have overstated the value of creating FWA opportunities in order to promote increased perceived fairness in relation to the distribution of work. Our findings provide new insights into how less structural determination in the design of work may require individuals and households to negotiate the design and extent of paid and unpaid work. In these negotiations, culturally scripted gender norms and practices may serve as guidelines but could inhibit the potentially positive effects of flexibility on gender equality. This cultural persistence of life-course patterns in 'doing gender' (Lyonette and Crompton 2015) results in FWA use failing to translate into a more equal distribution of paid and unpaid labour within family businesses. It could be suggested that fasterchanging gender norms towards equality are the starting point of the structural lag hypothesis. Hence, our study may be of interest not only to scholars of work and FWA researchers, but also to those involved in policymaking across different regions seeking to implement interventions to aid gender equality. Our findings questions long-assumed relationships between flexibility and gender equality and calls for a critical discussion about the actual and desired consequences of flexibility that closely attends to organisational, institutional and cultural differences.

Whilst our research was focused on a family business setting, we suggest that our findings may also be particularly relevant to other working environments that offer a high degree of autonomous work, which can align to concepts relating to 'structural lag', while also building upon strong tie relationships. For example, our research may also have key learnings and implications for specific close-knit work teams in larger organisations or start-up ventures who naturally have flatter organisational structures.

Our findings highlight key factors relating to organisational context which may influence FWA and therefore raise several questions for future research on work 
flexibility in organizations. For example, to what extent do informal relationships and connections within an organisation (such as friendships, kinship etc.) increase the use of FWA? What role does favouritism play in granting and using flexibility privileges? Or how might a caring organisational culture approximate an incentive structure for granting and using FWA similar to the situation found in business families? Furthermore, we suggest that more research is needed on how Covid-19 has influences practices and outcomes relating to the voluntary and involuntary use of FWA, and how it adapts over time (Kaduk et al. 2019). Studies should explore both the long-term effects of FWA on the individual/household, organizational and policy levels of structural constraints. Preliminary results suggest that the Covid-19 crises may have alleviated particular organizational constraints limiting FWA and could result in a higher acceptance of FWA use and better outcomes (Kraus et al. 2020; Shaw et al. 2020). Therefore, future research should explore whether higher use of FWA leads to consequences similar to what we have found for individuals working in their family's business.

\section{Appendix}

See Tables 2, 3, 4, 5 and 6.

Table 2 Descriptive statistics $(\mathrm{N}=674)$

\begin{tabular}{|c|c|c|c|c|}
\hline & RE & $\mathrm{FB}^{\mathrm{a}}$ & Owner-Manager ${ }^{\mathrm{a}}$ & Family employee \\
\hline \multicolumn{5}{|l|}{ Demographics } \\
\hline Women, in \% & 44.2 & 43.0 & 38.5 & 49.3 \\
\hline Age in years ${ }^{\mathrm{b}}$ & $33.9(7.3)$ & $34.2(6.9)$ & $35.8(5.8)^{* * *}$ & $31.9(7.7)^{* *}$ \\
\hline \multicolumn{5}{|l|}{ Family situation } \\
\hline Currently in relationship, in $\%$ & 78.2 & 80.2 & 80.9 & 79.1 \\
\hline $\begin{array}{l}\text { Minor children in household } \\
\text { in } \%\end{array}$ & 54.0 & 60.5 & $67.7 * *$ & 50.7 \\
\hline $\begin{array}{l}\text { Monthly net household equiv. } \\
\text { income in EUR }\end{array}$ & $1787(804.4)$ & $2040(2818.2)$ & $2219(3581.8)$ & 1781 (891.6) \\
\hline \multicolumn{5}{|l|}{ Flexible work arrangements } \\
\hline $\begin{array}{l}\text { 'Flex-time': flexible or no time } \\
\text { regulation in } \%\end{array}$ & 8.6 & $44.2^{* * * *}$ & $55.4 * * *$ & 28.9 *** \\
\hline $\begin{array}{l}\text { 'Flex-place': home-office option } \\
\text { in \% }\end{array}$ & 9.8 & $21.5^{* * * *}$ & $21.7^{* * * *}$ & $21.3 * *$ \\
\hline Commuting every weekday in $\%$ & 75.7 & 71.7 & 68.6 & 75.8 \\
\hline \multicolumn{5}{|l|}{ Work load } \\
\hline $\begin{array}{l}\text { Work hours per week respondent }{ }^{\mathrm{b}} \\
\text { in } \mathrm{h} / \mathrm{w}\end{array}$ & $37.3(13.0)$ & $42.6(18.2) * * *$ & $46.5(17.7)^{* * *}$ & $37.2(17.5)$ \\
\hline Marginal (1-14 h/w) in \% & 8.3 & 8.6 & 4.6 & 14.1 \\
\hline
\end{tabular}


Table 2 (continued)

\begin{tabular}{|c|c|c|c|c|}
\hline & $\mathrm{RE}$ & $\mathrm{FB}^{\mathrm{a}}$ & Owner-Manager $^{\mathrm{a}}$ & Family employee $^{\mathrm{a}}$ \\
\hline $\begin{array}{l}\text { Small part-time }(15-24 \mathrm{~h} / \mathrm{w}) \\
\text { in } \%\end{array}$ & 9.8 & 8.9 & 7.2 & 11.3 \\
\hline $\begin{array}{l}\text { Large part-time }(25-34 \mathrm{~h} / \mathrm{w}) \\
\text { in } \%\end{array}$ & 8.9 & 7.7 & 8.2 & 7.0 \\
\hline Fulltime $(35-49 \mathrm{~h} / \mathrm{w})$ in $\%$ & $57.0 * * *$ & $31.5^{* * *}$ & $26.2 * * *$ & $38.7 * * *$ \\
\hline Overwork $(50+\mathrm{h} / \mathrm{w})$ in $\%$ & 16.2 & $42.4^{* * *} *$ & $52.8^{* * * *}$ & $28.2 * *$ \\
\hline $\begin{array}{l}\text { Work hours per week partner }{ }^{b} \\
\text { in } h / w\end{array}$ & $31.7(17.1)$ & $35.5(19.2)^{*}$ & $32.3(18.8)$ & $40.4(18.8)^{* * *}$ \\
\hline Zero in $\%$ & 10.4 & 11.0 & 13.9 & 7.0 \\
\hline Marginal $(1-14 \mathrm{~h} / \mathrm{w})$ in $\%$ & 4.2 & $1.5^{*}$ & 1.5 & 1.4 \\
\hline $\begin{array}{l}\text { Small part-time }(15-24 \mathrm{~h} / \mathrm{w}) \\
\text { in } \%\end{array}$ & 3.9 & 5.0 & 6.2 & 3.5 \\
\hline $\begin{array}{l}\text { Large part-time }(25-34 \mathrm{~h} / \mathrm{w}) \\
\text { in } \%\end{array}$ & 6.5 & 5.3 & 7.2 & 2.8 \\
\hline Fulltime $(35-49 \mathrm{~h} / \mathrm{w})$ in $\%$ & 39.5 & 32.3 & 33.9 & 30.3 \\
\hline Overwork $(50+\mathrm{h} / \mathrm{w})$ in $\%$ & 6.2 & $18.1 * * *$ & $13.9 * *$ & $23.9 * * *$ \\
\hline $\begin{array}{l}\text { Combined work hours for } \\
\text { couples }^{b, c} \text { in } h / w\end{array}$ & $69.7(18.5)$ & $78.1(21.7)^{* * *}$ & $78.7(22.5)^{* * *}$ & $77.3(18.5)^{* *}$ \\
\hline Part-timers in $\%$ & 3.4 & 1.6 & 2.0 & 1.0 \\
\hline Traditional respondent in $\%$ & 31.9 & 29.8 & 36.1 & $20.4^{*}$ \\
\hline Traditional partner in $\%$ & 21.9 & 25.3 & 19.1 & $24.7^{*}$ \\
\hline Dual careers in $\%$ & 42.9 & 43.3 & 42.9 & 43.9 \\
\hline \multicolumn{5}{|l|}{ Gender equality } \\
\hline \multicolumn{5}{|c|}{ 'Equality-duties': housework is done } \\
\hline $\begin{array}{l}\text {... by tendency by the partner } \\
\text { in } \%\end{array}$ & 40.3 & 42.3 & 48.1 & 33.3 \\
\hline ... half-half in $\%$ & 28.6 & $19.1^{*}$ & 20.3 & $17.3^{*}$ \\
\hline $\begin{array}{l}\ldots \text { by tendency by the respond- } \\
\text { ent in } \%\end{array}$ & 30.6 & 38.2 & 30.8 & $49.4 * *$ \\
\hline \multicolumn{5}{|c|}{ 'Equality-fairness': fairness of labour division } \\
\hline $\begin{array}{l}\ldots \text { I do more than my fair share } \\
\text { in } \%\end{array}$ & 21.0 & $12.7^{*}$ & $12.0^{*}$ & 13.8 \\
\hline ... I do about my fair share in $\%$ & 66.8 & $78.2 * *$ & 75.9 & $81.6^{*}$ \\
\hline $\begin{array}{l}\text {... I do less than my fair share } \\
\text { in } \%\end{array}$ & 12.2 & 9.1 & 12.0 & $4.6^{*}$ \\
\hline \multicolumn{5}{|l|}{ Goals } \\
\hline $\begin{array}{l}\text { Importance of education or } \\
\text { career interests }\end{array}$ & $3.7(1.6)$ & $3.9(1.7)$ & $4.2(1.9)^{* *}$ & $3.6(1.4)$ \\
\hline
\end{tabular}

Bivariate distributions of variables included in the multivariate models, all values are unweighted. a We applied two-tailed t-tests to interval-scaled variables and Chi-square-tests to binary and categorial variables to evaluate the significance of differences of RE versus FB, FB owner-managers, and FB family employees. Probability levels for two-tailed t-tests/ Chi-square-tests: ${ }^{*} p<0.05 ;{ }^{*} p<0.01 ;{ }^{*} * p<0.001$. b For all interval-scaled variables, we report means followed by the standard deviation in brackets. c We combined self-reported work hours of respondents and their partner by adding up the respective work hours. $\mathrm{d}$ Respondents had to divide 15 importance-tokens between five areas. Source PAIRFAM release 5.0, own calculations 
Table 3 Comparison of key matching variables before and after matching

\begin{tabular}{|c|c|c|c|c|c|c|}
\hline & \multicolumn{3}{|c|}{ Pre-matching } & \multicolumn{3}{|c|}{ Post-matching } \\
\hline & $\mathrm{RE}$ & FB & All & $\mathrm{RE}$ & FB & All \\
\hline \multicolumn{7}{|l|}{ Cohort in $\%$} \\
\hline 1991-1993 & 21.9 & 11.1 & 20.6 & 14.8 & 11.9 & 13.4 \\
\hline 1981-1983 & 35.7 & 34.6 & 35.6 & 32.6 & 35.6 & 34.1 \\
\hline $1971-1973$ & 42.4 & 54.3 & 43.8 & 52.5 & 52.5 & 52.5 \\
\hline $\mathrm{N}$ & 3002 & 396 & 3398 & 337 & 337 & 674 \\
\hline \multicolumn{7}{|l|}{ Gender in $\%$} \\
\hline Male & 54.0 & 57.8 & 54.4 & 55.8 & 57.0 & 56.4 \\
\hline Female & 46.0 & 42.2 & 45.6 & 44.2 & 43.0 & 43.6 \\
\hline $\mathrm{N}$ & 3002 & 396 & 3398 & 337 & 337 & 674 \\
\hline \multicolumn{7}{|l|}{ Region in \% } \\
\hline West & 69.0 & 62.6 & 68.3 & 59.4 & 62.3 & 60.8 \\
\hline East & 31.0 & 37.4 & 31.7 & 40.7 & 37.7 & 39.2 \\
\hline $\mathrm{N}$ & 3002 & 396 & 3398 & 337 & 337 & 674 \\
\hline \multicolumn{7}{|l|}{ Community size in $\%$} \\
\hline$>500,000$ inhabitants & 31.4 & 27.3 & 30.9 & 23.4 & 25.8 & 24.6 \\
\hline $50,000-500,000 \mathrm{inh}$ & 39.8 & 39.4 & 39.8 & 36.2 & 38.0 & 37.1 \\
\hline$<50,000$ inhabitants & 28.9 & 33.3 & 39.4 & 40.4 & 36.2 & 38.3 \\
\hline $\mathrm{N}$ & 3002 & 396 & 3398 & 337 & 337 & 674 \\
\hline \multicolumn{7}{|l|}{ Education in \% } \\
\hline In training & 13.9 & 7.6 & 13.2 & 10.7 & 7.7 & 9.2 \\
\hline No certificate & 8.7 & 10.1 & 8.9 & 7.4 & 8.3 & 7.9 \\
\hline Vocational training & 40.6 & 37.1 & 40.2 & 41.5 & 38.0 & 39.8 \\
\hline Vocational school & 12.3 & 10.9 & 12.1 & 12.5 & 10.1 & 11.3 \\
\hline Technical school & 6.1 & 18.4 & 7.6 & 8.0 & 20.2 & 14.1 \\
\hline Technical college & 7.7 & 7.8 & 7.7 & 8.6 & 7.1 & 7.9 \\
\hline University & 9.5 & 7.3 & 9.2 & 10.4 & 7.7 & 9.1 \\
\hline PHD & 1.2 & 0.8 & 1.2 & 0.9 & 0.9 & 0.9 \\
\hline $\mathrm{N}$ & 3002 & 396 & 3398 & 337 & 337 & 674 \\
\hline \multicolumn{7}{|l|}{ Migration status in \% } \\
\hline No migration history & 81.4 & 80.9 & 81.3 & 84,6 & 83.1 & 83.8 \\
\hline 1st generation & 9.5 & 9,8 & 9.6 & 7.7 & 8.3 & 8.0 \\
\hline 2nd generation & 9.1 & 9.3 & 9.1 & 7.7 & 8.6 & 8.2 \\
\hline \multirow[t]{3}{*}{$\mathrm{N}$} & 2915 & 388 & 3303 & 337 & 337 & 674 \\
\hline & \multicolumn{3}{|c|}{ Pre-matching } & \multicolumn{3}{|c|}{ Post-matching } \\
\hline & RE & FB & All & $\mathrm{RE}$ & FB & All \\
\hline \multicolumn{7}{|l|}{ Selected occupations (ISCO-codes) in $n$} \\
\hline Shop sales assistants & 9.1 & 8.6 & & 8.9 & 7.4 & \\
\hline Mixed crop and animal producers & 0.3 & 5.0 & & 0.9 & 5.0 & \\
\hline General office clerks & 3.8 & 3.8 & & 3.3 & 4.2 & \\
\hline Managing directors and chief executives & 0.4 & 2.5 & & 1.2 & 3.0 & \\
\hline
\end{tabular}


Table 3 (continued)

\begin{tabular}{|c|c|c|c|c|c|c|}
\hline & \multicolumn{3}{|c|}{ Pre-matching } & \multicolumn{3}{|c|}{ Post-matching } \\
\hline & $\mathrm{RE}$ & FB & All & $\mathrm{RE}$ & FB & All \\
\hline Secretaries (general) & 3.2 & 2.5 & & 4.5 & 2.7 & \\
\hline Restaurant managers & 0.1 & 2.3 & & 0.0 & 2.4 & \\
\hline Construction supervisors & 0.2 & 2.3 & & 1.2 & 2.4 & \\
\hline Medical assistants & 2.9 & 2.3 & & 2.4 & 2.4 & \\
\hline Manufacturing supervisors & 0.5 & 2.0 & & 1.2 & 1.8 & \\
\hline Statistical. finance and insurance clerks & 0.9 & 2.0 & & 1.8 & 2.4 & \\
\hline Waiter & 1.3 & 2.0 & & 1.8 & 2.1 & \\
\hline Beauticians and related workers & 0.1 & 2.0 & & 0.0 & 2.4 & \\
\hline Commercial sales representatives & 0.8 & 1.5 & & 1.5 & 1.8 & \\
\hline Hairdressers & 0.5 & 1.5 & & 0.9 & 0.9 & \\
\hline Gardeners \& growers & 0.6 & 1.5 & & 0.3 & 1.8 & \\
\hline Cabinet-makers and related workers & 0.9 & 1.5 & & 0.6 & 1.8 & \\
\hline Graphic and multimedia designers & 0.2 & 1.3 & & 0.0 & 1.5 & \\
\hline Journalists & 0.4 & 1.3 & & 0.9 & 1.5 & \\
\hline Photographers & 0.0 & 1.3 & & 0.0 & 1.5 & \\
\hline Child care workers & 1.3 & 1.3 & & 0.0 & 1.5 & \\
\hline \multicolumn{7}{|l|}{ Professional education father in $\%$} \\
\hline No certificate & 9.1 & 10.0 & 9.2 & 8.0 & 10.4 & 9.2 \\
\hline Vocational training & 55.4 & 44.4 & 54.1 & 55.5 & 43.0 & 49.3 \\
\hline Vocational school & 8.3 & 10.9 & 8.6 & 5,9 & 11.6 & 8.8 \\
\hline Technical school & 9.0 & 16.6 & 9.9 & 10.7 & 16.6 & 13.7 \\
\hline Civil service training & 2.6 & 1.4 & 2.4 & 3.3 & 1.5 & 2.4 \\
\hline Technical college & 6.9 & 5.8 & 6.7 & 8.0 & 5.6 & 6.8 \\
\hline University & 7.8 & 9.7 & 8.0 & 7.7 & 10.1 & 8.9 \\
\hline PHD & 1.1 & 1.1 & 1.1 & 0.9 & 1.2 & 1.0 \\
\hline $\mathrm{N}$ & 2702 & 360 & 3062 & 337 & 337 & 674 \\
\hline \multicolumn{7}{|l|}{ Professional education mother in $\%$} \\
\hline No certificate & 16.6 & 16.1 & 16.6 & 16.0 & 15.4 & 15.7 \\
\hline Vocational training & 50.9 & 51.2 & 50.0 & 52.2 & 51.9 & 51.9 \\
\hline Vocational school & 16.3 & 15.0 & 16.1 & 13.7 & 15.1 & 14.4 \\
\hline Technical school & 4.1 & 3.8 & 4.0 & 6.5 & 4.2 & 5.3 \\
\hline Civil service training & 1.0 & 0.5 & 0.9 & 0.9 & 0.3 & 0.6 \\
\hline Technical college & 5.3 & 5.4 & 5.3 & 5.9 & 5.3 & 5.6 \\
\hline University & 5.3 & 7.8 & 5.6 & 4.5 & 7.7 & 6.1 \\
\hline PHD & 0.6 & 0.3 & 0.6 & 0.3 & 0.3 & 0.3 \\
\hline $\mathrm{N}$ & 2837 & 373 & 3210 & 337 & 337 & 674 \\
\hline
\end{tabular}

The reported ISCO-codes are the twenty most frequent within the pre-matched FB sample. The complete list of reported ISCO codes is available upon request. Source PAIRFAM release 5.0, own calculations 
Table 4 Comparison of occupational status: FB versus RE

\begin{tabular}{|c|c|c|c|c|}
\hline & \multicolumn{2}{|c|}{ Family business } & \multicolumn{2}{|c|}{$\begin{array}{l}\text { Regular } \\
\text { employment }\end{array}$} \\
\hline & $\mathrm{n}$ & $\%$ & $\mathrm{n}$ & $\%$ \\
\hline Self-employed farmers with no employees & 7 & 2.1 & & \\
\hline Self-employed farmers with 1-9 employees & 10 & 3.0 & & \\
\hline Self-employed academic professionals with no employees & 1 & 0.3 & 5 & 1.5 \\
\hline Self-employed academic professionals with 1-9 employees & & & 1 & 0.3 \\
\hline Other self-employed with no employees & 120 & 35.6 & & \\
\hline Other self-employed with 1-9 employees & 66 & 19.6 & & \\
\hline Other self-employed with 10 and more employees & 11 & 3.3 & & \\
\hline Unpaid family workers & 5 & 1.5 & 1 & 0.3 \\
\hline Industry and works foremen in a salaried position & 1 & 0.3 & 2 & 0.6 \\
\hline Employees with simple duties & 11 & 3.3 & 38 & 11.3 \\
\hline Employees with qualified duties & 28 & 8.3 & 104 & 30.9 \\
\hline Employees with highly qualified duties or managerial functions & 9 & 2.7 & 53 & 15.7 \\
\hline Employees with comprehensive leadership functions & 5 & 1.5 & 4 & 1.2 \\
\hline Untrained workers & & & 9 & 2.7 \\
\hline Workers with on-the-job training & 8 & 2.4 & 23 & 6.8 \\
\hline Formally trained and specialized workers & 13 & 3.9 & 61 & 18.1 \\
\hline Foremen & 1 & 0.3 & 6 & 1.8 \\
\hline Master craftsmen & 4 & 1.2 & 5 & 1.5 \\
\hline Apprentices/trainees in trade, commerce, or public administration & 3 & 0.9 & 12 & 3.6 \\
\hline Apprentices/trainees in crafts and production & 7 & 2.1 & 11 & 3.3 \\
\hline Apprentices/trainees in home economics or agriculture & 2 & 0.6 & 1 & 0.3 \\
\hline Volunteers, interns, etc & & & 1 & 0.3 \\
\hline (Missing) & 25 & 7.4 & & \\
\hline Total & 337 & 100.0 & 337 & 100.0 \\
\hline
\end{tabular}


Table 5 Comparison of occupational classification (ISCO) within FB: owner-managers versus family employees

\begin{tabular}{|c|c|c|c|c|c|}
\hline \multicolumn{3}{|l|}{ Owner-managers } & \multicolumn{3}{|l|}{ Family employees } \\
\hline ISCO-code & $\mathrm{n}$ & $\%$ & ISCO-code & $\mathrm{n}$ & $\%$ \\
\hline 1120 Managing directors and CEOs & 7 & 3.59 & 1120 Managing directors and CEOs & 3 & 2.11 \\
\hline 1412 Restaurant managers & 7 & 3.59 & & & \\
\hline $\begin{array}{l}2166 \text { Graphic and multimedia design- } \\
\text { ers }\end{array}$ & 4 & 2.05 & & & \\
\hline 2265 Dieticians and nutritionists & 3 & 1.54 & & & \\
\hline 2642 Journalists & 5 & 2.56 & & & \\
\hline $\begin{array}{l}2652 \text { Musicians, singers and compos- } \\
\quad \text { ers }\end{array}$ & 4 & 2.05 & & & \\
\hline 3122 Manufacturing supervisors & 3 & 1.54 & 3122 Manufacturing supervisors & 3 & 2.11 \\
\hline 3123 Construction supervisors & 6 & 3.08 & & & \\
\hline 3256 Medical assistants & 3 & 1.54 & 3256 Medical assistants & 5 & 3.52 \\
\hline 3322 Commercial sales representatives & 6 & 3.08 & $\begin{array}{l}3313 \text { Accounting associate profes- } \\
\text { sionals }\end{array}$ & 3 & 2.11 \\
\hline 3431 Photographers & 5 & 2.56 & 4110 General office clerks & 14 & 9.86 \\
\hline 4312 Statistical, finance and insurance & 7 & 3.59 & 4120 Secretaries (general) & 9 & 6.34 \\
\hline 4323 Transport clerks & 3 & 1.54 & 5131 Waiters & 6 & 4.23 \\
\hline 5142 Beauticians and related workers & 7 & 3.59 & & & \\
\hline 5223 Shop sales assistants & 16 & 8.21 & 5223 Shop sales assistants & 9 & 6.34 \\
\hline 5311 Child care workers & 4 & 2.05 & & & \\
\hline $\begin{array}{l}6113 \text { Gardeners, horticultural and } \\
\text { nurse }\end{array}$ & 5 & 2.56 & & & \\
\hline 6130 Mixed crop and animal producers & 9 & 4.62 & 6130 Mixed crop and animal producers & 8 & 5.63 \\
\hline 7123 Plasterers & 3 & 1.54 & 7112 Bricklayers and related workers & 4 & 2.82 \\
\hline $\begin{array}{l}7522 \text { Cabinet-makers and related } \\
\text { workers }\end{array}$ & 4 & 2.05 & 7411 Building and related electricians & 3 & 2.11 \\
\hline $\begin{array}{l}7549 \text { Craft and related workers not } \\
\text { else }\end{array}$ & 3 & 1.54 & & & \\
\hline Total & 114 & & & 67 & \\
\hline
\end{tabular}

ISCO-codes are only presented if their prevalence within each subgroup is three or more. The complete list of reported ISCO codes is available upon request. Source PAIRFAM release 5.0, own calculations 


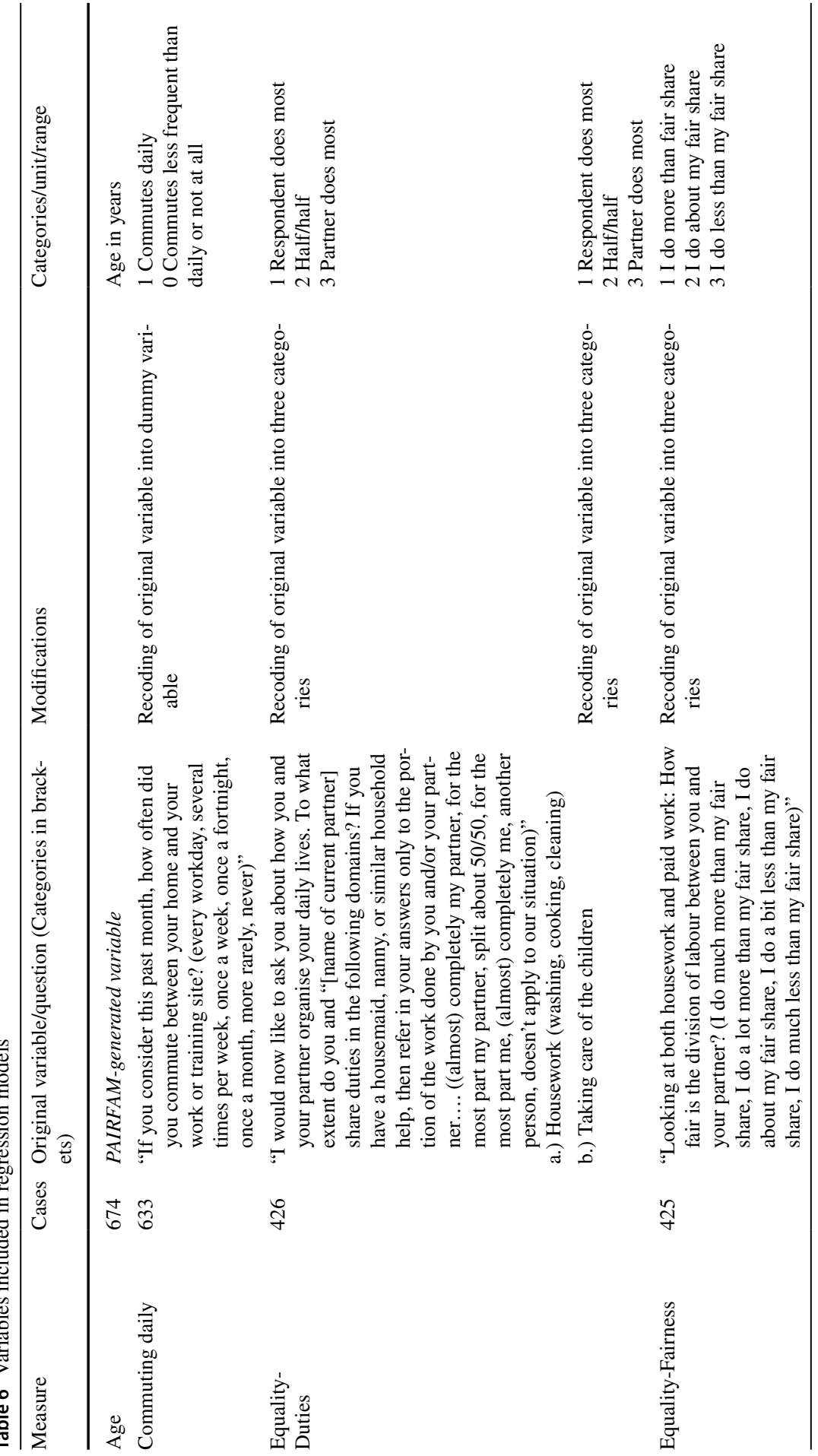




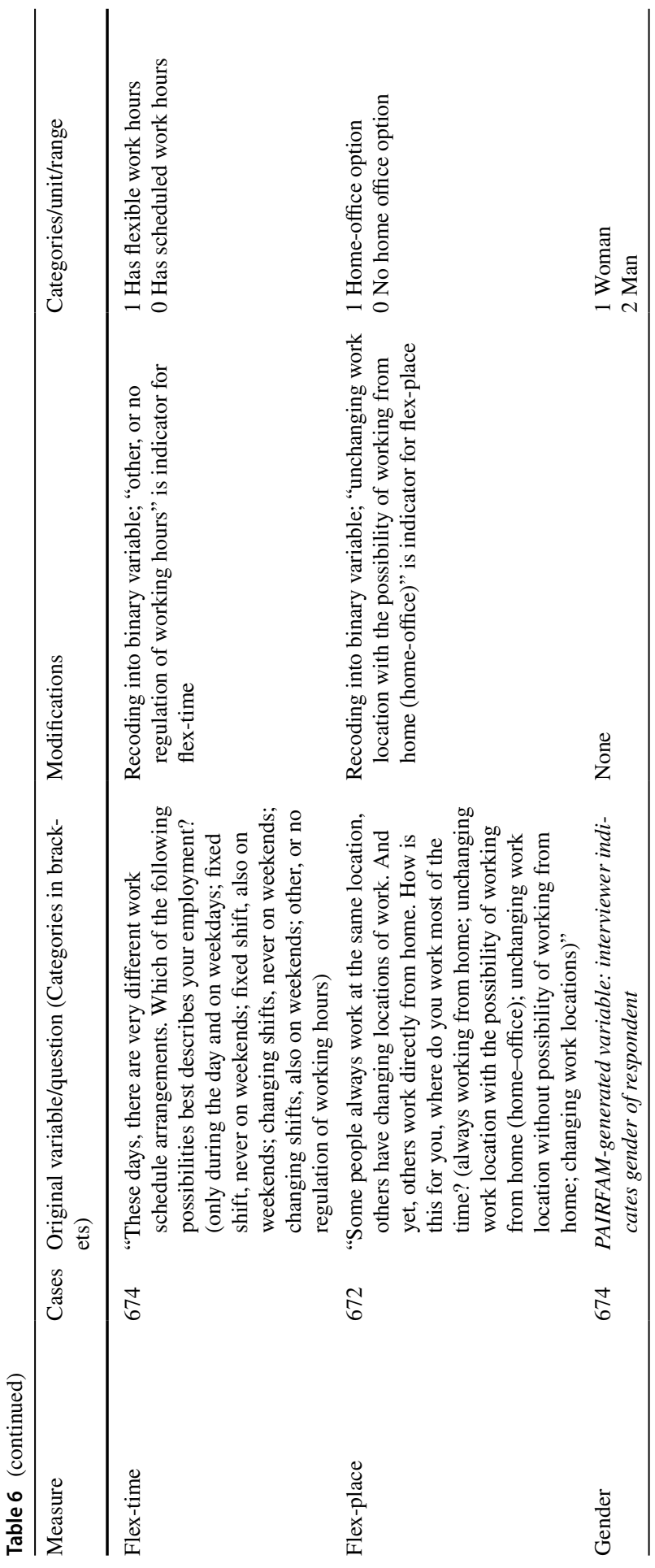



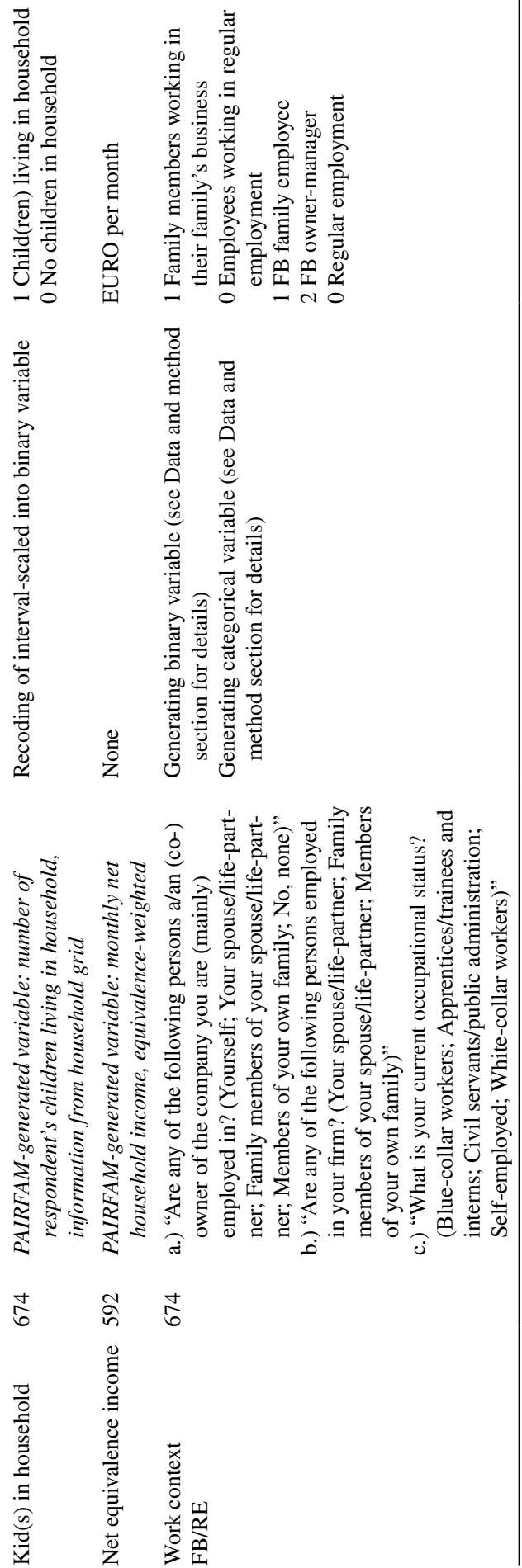


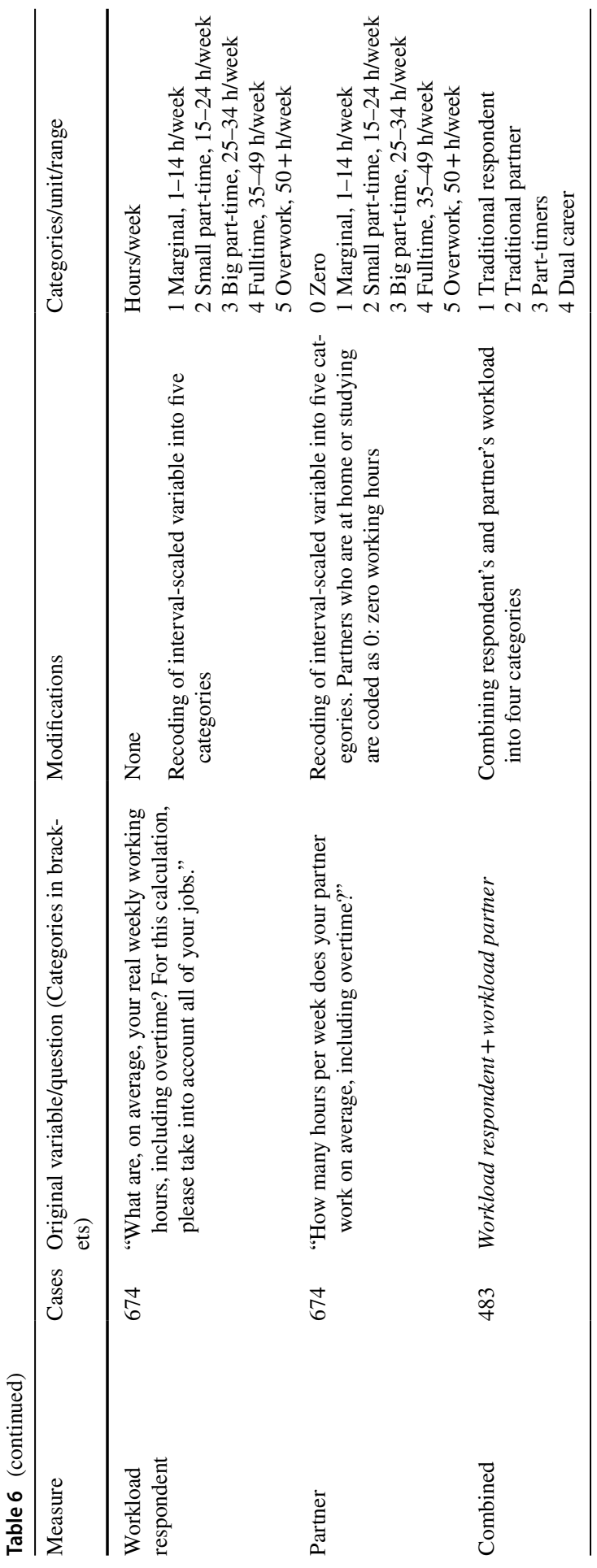




\section{References}

Allen TD, Johnson RC, Kiburz KM, Shockley KM (2013) Work-family conflict and flexible work arrangements: deconstructing flexibility. Pers Psychol 66(2):345-376

Allmendinger J (2021) Es Geht Nur Gemeinsam! Wie Wir Endlich Geschlechtergerechtigkeit Erreichen, Ullstein, Berlin

Allmendinger J, Ebner C (2006) Arbeitsmarkt und demografischer Wandel. Zeitschrift Für Arbeits- Und Organisationspsychologie 50(4):227-239

Annink A, Den Dulk L, Steijn B (2016) Work-family conflict among employees and the self-employed across Europe. Soc Indic Res 126(2):571-593

Astrachan J, Shanker MC (2003) Family businesses' contribution to the U.S. economy: a closer look. Fam Bus Rev 16(3):211-19

Bagger J, Li A (2014) How does supervisory family support influence employees' attitudes and behaviors? J Manag 40(4):1123-1150

Beck U (1992) Risk society. Towards a new modernity. Sage, London

Becker SO, Caliendo M (2007) Sensitivity analysis for average treatment effects. Stand Genomic Sci 7(1):71-83

Beigi M, Shirmohammadi M, Stewart J (2018) Flexible work arrangements and work-family conflict: a metasynthesis of qualitative studies among academics. Hum Resour Dev Rev 17(3):314-336

Bernhard F (2011) Psychological ownership in family businesses. Three essays on antecedents and consequences. EBS, Oestrich-Winkel

Bernhard F, O’Driscoll MP (2011) Psychological ownership in small family-owned businesses: leadership style and nonfamily-employees' work attitudes and behavior. Group Org Manag 36(3):345-384

Bertoni F, Marti J, Reverte C (2019) The impact of government-supported participative loans on the growth of entrepreneurial ventures. Res Policy 48(1):371-384

Blair-Loy M (2010) Work without end? Scheduling flexibility and work-to-family conflict among stockbrokers. Work Occup 36(4):279-317

Caliendo M, Kopeinig S (2005) Some practical guidance for the implementation of propensity score matching. Discussion Paper 1588, Institute for the Study of Labor, Berlin

Castells M (2010) The power of identity. Blackwell, Malden, MA

Choi H, Burgard S, Elo IT, Heisler M (2015) Are older adults living in more equal counties healthier than older adults living in more unequal counties? A propensity score matching approach. Soc Sci Med 141:82-90

Chua JH, Chrisman JJ, Sharma P (1999) Defining the family business by behaviour. Entrep Theory Pract 24(4):19-39

Chung GH, Pak J (2021) Is there internal fit among ability-, motivation-, and opportunity-enhancing HR practices? Evidence from South Korea. RMS 15(7):2049-2074

Chung H, van der Lippe T (2018) Flexible working, work-life balance, and gender equality: Introduction. Soc Indic Res 151:365-381

Chung H, van der Lippe T (2020) Flexible working, work-life balance, and gender equality. Soc Indic Res 151(2):365-381

Cooper R, Baird M (2015) Bringing the 'right to request' flexible working arrangements to life. Empl Relat 37(5):568-581

Cooper JT, Kidwell RE, Eddleston KA (2013) Boss and parent, employee and child. Fam Relat 62(3):457-471

Correll SJ, Kelly EL, Trimble O’Connor L, Williams JC (2014) Redesigning, redefining work. Work Occup 41(1):3-17

De Menezes LM, Kelliher C (2011) Flexible working and performance: a systematic review of the evidence for a business case. Hum Resour Manage 13(4):452-474

De Menezes LM, Kelliher C (2017) Flexible working, individual performance and employee attitudes: comparing formal and information arrangements. Hum Resour Manage 56(6):1051-1070

Dehajia RH, Wahba S (2002) Propensity score-matching methods for nonexperimental causal studies. Rev Econ Stat 84(1):151-161

Dinh H, Strazdins L, Welsh J (2017) Hour-glass ceilings: work-hour thresholds, gendered health inequities. Soc Sci Med 176(1):42-51

Dreyer R, Busch C (2021) At the heart of family businesses: how copreneurs craft work-life balance. J Fam Bus Manag. https://doi.org/10.1108/JFBM-12-2020-0113 
Eddleston KA, Powell GN (2012) Nurturing entrepreneurs' work-family balance. Entrep Theory Pract 36(3):513-541

Elder GH, Kirkpatrick Johnson M, Crosnoe R (2003) The emergence and development of life course theory. In: Mortimer JS, M. (eds) Handbook of the life course. Kluwer Academic, New York, pp 3-22

Fagnani J (2012) Recent reforms in childcare and family policies in France and Germany. Comparative Child Fam Policy 34(3):509-516

Ferraro H, Marrone J (2016) Examining employment relationship activities in family business research. J Fam Bus Manag 6(3):210-224

Freidson E (1984) The changing nature of professional control. Ann Rev Sociol 10(3):1-20

Gerards R, van Wetten S, van Sambeek C (2021) New ways of working and intrapreneurial behaviour: the mediating role of transformational leadership and social interaction. RMS 15(7):2075-2110

Gersick KE, Davis JA, McCollom Hampton M, Lansberg I (1997) Generation to generation. Harvard Business School Press, Boston

Glass JL (2004) Blessing or curse? Work-family policies and mother's wage growth over time. Work Occup 31(3):367-394

Golden L (2001) Flexible work schedules. Am Behav Sci 44(7):1157-1178

Gottschalk S, Keese D (2011) Die volkswirtschaftliche Bedeutung von Familienunternehmen. Munich

Grunow D, Hofmeister H, Buchholz S (2006) Late 20th-century persistence and decline of the female homemaker in Germany and the United States. Int Sociol 21(1):101-131

Hari A (2017) Who gets to 'work hard, play hard'? Gend Work Organ 24(2):99-114

Haynes DC, Avery RJ, Hunts HJ (1999) The decision to outsource child care in households engaged in a family business. Fam Bus Rev 12(1):269-281

Hilbrecht M, Lero DS (2014) Self-employment and family life. Community Work Fam 17(1):20-42

Hochschild AR (1997) When work becomes home and home becomes work. Calif Manage Rev 39(4):79-97

Houshmand M, Seidel MDL, Ma DG (2017) The impact of adolescent work in family business on child-parent relationships and psychological well-being. Fam Bus Rev 30(3):242-261

Huinink J, Brüderl J, Nauck B, Walper S, Castiglioni L, Feldhaus M (2011) Panel analysis of intimate relationships and family dynamics (PAIRFAM). Zeitschrift Für Familienforschung 23(1):77-101

Hundley G (2000) Male/female earnings differences in self-employment. Ind Labor Relat Rev 54(1):95-114

Jaskiewicz P, Uhlenburck K, Balkin D, Reay T (2013) Is nepotism good or bad? Fam Bus Rev 26(2):121-139

Jennings JE, Breitkreuz RS, James AE (2013) When family members are also business owners: is entrepreneurship good for families? Fam Relat 62(3):472-489

Jung Jan S, Zippay A, Park R (2012) Family roles as moderators of the relationship between schedule flexibility and stress. J Marriage Fam 74(4):897-912

Kaduk A, Genadek K, Kelly EL, Moen P (2019) Involuntary vs voluntary flexible work: insights for scholars and stakeholders. Commu Work Fam 22(4):412-442

Kanter RM (1977) Work and family in the United States. Russel Sage Foundation

Kelly EL, Moen P (2007a) Rethinking the clockwork of work. Adv Dev Hum Resour 9(4):487-506

Kelly EL, Moen P (2007b) Rethinking the clockwork of work: why schedule control may pay off at work and at home. Adv Dev Hum Resour 9(4):487-506

Kelly EL, Moen P (2020) Overload: how good jobs went bad and what we can do about it. Princeton University Press, Princeton, Oxford

Kelly EL, Moen P, Tranby E (2011) Changing workplaces to reduce work-family conflict: schedule control in a white-collar organization. Am Sociol Rev 76:265-290

Kelly CM, Rofcanin Y, Las Heras M, Ogbonnaya C, Marescaux E, Kreis MJB (2019) Seeking an "i-deal" balance. J Vocational Behav 118:103369

Kim H, Gong Y (2016) Effects of work-family and family-work conflicts on flexible work arrangements demand. Int J Human Resour Manag 28(20):1-21

King V, Elder GH (1995) American children view their grandparents. J Marriage Fam 57(1):165-178

Kohli M (2007) The institutionalization of the life course: looking back to look ahead. Res Hum Dev 4(3-4):253-271

König S, Cesinger B (2015) Gendered work-family conflict in Germany: do self-employment and flexibility matter? Work Employ Soc 29(4):531-549 
Köppen K, Trappe H (2019) The gendered division of labor and its perceived fairness: Implications for childbearing in Germany. Demogr Res 40:1413-1440

Korunka C (2021) Flexible working practices and approaches. Psychological and social implications, Springer Cham, Springer Nature Switzerland

Kossek E, Lautsch B (2017) Work-life flexibility for whom? Acad Manag Ann 12(1):5-36

Kraus S, Clauss T, Breier M, Gast J, Zardini A, Tiberius V (2020) The economics of covid-19: Initial empirical evidence on how family firms in five European countries cope with the corona crisis. Int J Entrep Behav Res 26(5):1067-1092

Kushins ER, Behounek E (2020) Using sociological theory to problematize family business research. J Fam Bus Strat 11(1):1-9

Lambert AD, Marler JH, Gueutal HG (2008) Individual differences: factors affecting employee utilization of flexible work arrangements. J Vocat Behav 73(1):107-117

Langner LA (2017) Flexible men and successful women. Work Employ Soc 32(4):687-706

Lapierre LM, Allen TD (2012) Control at work, control at home, and planning behavior. J Manag 38(5):1500-1516

Leitner S (2004) Varieties of familialism. Eur Soc 5(4):353-375

Lofstrom M, Bates T, Parker SC (2014) Why are some people more likely to become small-businesses owners than others? J Bus Ventur 29(2):232-251

Loscocco KA, Bird SR (2012) Gendered path: why women lag behind men in small business success. Work Occup 39(2):183-219

Lott Y, Chung H (2016) Gender discrepancies in the outcomes of schedule control on overtime hours and income in Germany. Eur Sociol Rev 32(6):757-765

Lyonette C, Crompton R (2015) Sharing the load? Partners' relative earnings and the division of domestic labour. Work Employ Soc 29(1):23-40

Markoczy L, Deeds DL (2009) Theory building at the intersection: recipe for impact or road to nowhere. J Manage Stud 46(6):1076-1088

Matta VI (2015) Führen selbstgesteuerte Arbeitszeiten zu einer Ausweitung der Arbeitsstunden? Z Soziol 44(4):253-271

McKinsey (2020). What's next for remote work: an analysis of 2000 tasks, 800 jobs, and nine countries, McKinsey Global Institute, Available online: https://www.mckinsey.com/ /media/mckin sey/featured $\% 20$ insights/future $\% 20$ of $\% 20$ organizations/whats $\% 20$ next $\% 20$ for $\% 20$ remote $\%$ 20work\%20an\%20analysis\%20of\%202000\%20tasks\%20800\%20jobs\%20and\%20nine $\% 20$ cou ntries/whats_next_for_remote_work_f.pdf?shouldIndex $=$ false $(12$ th Nov, 2021)

Moen P (2015) An institutional/organizational turn. Work Occup 42(2):174-182

Moen P (2016) Work over the gendered life course. In: Shanahan MJ, Mortimer JT, Kirkpatrick Johnson M (eds) Handbook of the life course. Springer, Cham, pp 249-275

Moen P, Orrange RM (2002) Careers and lives: socialization, structural lag, and gendered ambivalence. Adv Life Course Res 7:231-260

Moen P, Roehling P (2005) The career mystique. Rowman \& Littlefield Publishers, Lanham

Morgan SL, Harding DJ (2006) Matching estimators of causal effects. Sociological Methods Res 35(3):3-60

Munsch CL (2016) Flexible work, flexible penalties: the effect of gender, childcare, and type of request on the flexibility bias. Soc Forces 94(4):1567-1591

Munsch CL, Ridgeway CL, Williams IC (2014) Pluralistic ignorance and the flexibility bias. Work Occup 41(1):40-62

Neckebrouck J, Schulze W, Zellweger T (2018) Are family firms good employers? Acad Manag J 61(2):553-585

Peretz H, Fried Y, Levi A (2018) Flexible work arrangements, national culture, organisational characteristics, and organisational outcomes: a study across 21 countries. Hum Resour Manag J 28(1):183-200

Pines AM, Lerner M, Schwartz D (2010) Gender differences in entrepreneurship. Equal Divers Incl 29(2):186-198

Riley MW, Kahn RL, Foner A (1994) Age and structural lag. John Wiley \& Sons, New York

Rofcanin Y, Anand S (2020) Human relations virtual special issue: flexible work practices and workfamily domain. Hum Relat 73(8):1182-2285

Rosenbaum PR (2002) Overt bias in observational studies. In: Observational studies: Springer, New York, pp 71-104 
Rosenbaum PR, Rubin DB (1984) Reducing bias in observational studies using subclassification on the propensity score. J Am Stat Assoc 79(387):516-524

Rothausen T (2009) Management work-family research and work-family fit. Fam Bus Rev 22(3):220-234

Rovelli P, Ferasso M, De Massis A, Kraus S (2021) Thirty years of research in family business journals: status quo and future directions. J Fam Bus Strategy. https://doi.org/10.1016/j.jfbs.2021. 100422

Schieman S, Glavin P (2016) The pressure-status nexus and blurred work-family boundaries. Work Occup 43(1):3-37

Schröder E, Schmitt-Rodermund E (2013) Antecedents and consequences of adolescents' motivations to join the family business. J Vocat Behav 83(3):476-485

Shane S, Venkataraman S (2000) The promise of entrepreneurship as a field of research. Acad Manag Rev 25(1):217-226

Shaw WS, Main CJ, Findley PA (2020) Opening the workplace after COVID-19: what lessons can be learned from return-to-work research? J Occup Rehabil 30:299-302

Shockley KM, Allan TD (2010) Investigating the missing link in flexible work arrangement utilization. J Vocat Behav 76(3):131-142

Sieger P, Bernhard F, Frey U (2011) Affective commitment and job satisfaction among non-family employees. J Fam Bus Strat 2:78-89

Stamm I (2016) Coordination tasks and negotiation modes of linked lives in entrepreneurial families. J Marriage Fam 78(4):939-956

Stamm I, Bernhard F, Hameister N (2019) Empirische Befunde zu Unternehmerfamilien in Deutschland. In: Kleve H, Köllner T (eds) Soziologie der Unternehmerfamilie. Springer VS, Wiesbaden, pp 115-141

Teoh WMY, Chong CW, Chong SC, Ismail H (2016) Managing work-family conflict among entrepreneurs. Int J Bus Manag 11(9):179-191

Thébaud S, Halcomb L (2019) One step forward? Advances and setbacks on the path toward gender equality in families and work. Sociol Compass 13(6):e12700

Tomlinson J, Baird M, Berg P, Cooper R (2018) Flexible careers across the life course: advancing theory, research and practice. Human Relations 71(1):4-22

van der Lippe T, Lippényi Z (2020) Beyond formal access: organizational context, working from home, and work-family conflict of men and women in European workplaces. Soc Indic Res 151(2):383-402

Walby S (2011) Is the knowledge society gendered? Gend Work Organ 18(1):1-29

Wheatley D (2017) Employee satisfaction and use of flexible working arrangements. Work Employ Soc 31(4):567-585

Yang TT, Aldrich HE (2014) Who's the boss? Explaining gender inequality in entrepreneurial teams. Am Sociol Rev 79(2):303-327

Publisher's Note Springer Nature remains neutral with regard to jurisdictional claims in published maps and institutional affiliations. 


\section{Authors and Affiliations}

\section{Isabell K. Stamm ${ }^{1} \cdot$ Fabian Bernhard $^{2}$ D $\cdot$ Nicole Hameister $^{3} \cdot$ Kristel Miller $^{4}$}

Isabell K. Stamm

isabell.stamm@tu-berlin.de

Nicole Hameister

nicole.hameister@dza.de

Kristel Miller

k.miller@ulster.ac.uk

1 Department of Sociology, Technical University Berlin, Fraunhoferstraße 33-36, 10587, Berlin, Germany

2 Family Business Center, EDHEC Business School, 18, rue du Quatre Septembre, 75002 Paris, France

3 German Centre of Gerontology, Manfred-von-Richthofen-Straße 2, 12101 Berlin, Germany

4 Department of Management, Leadership and Marketing, Ulster University, Jordanstown Campus, Shore Road, Newtownabbey BT37 0QB, UK 